\title{
PENGEMBANGAN WISATA RELIGI GUA MARIA GOLO CURU DI KOTA RUTENG, MANGGARAI, NUSA TENGGARA TIMUR
}

Yohana Stefania Hasiman a, 1 , I Putu Anom a, 2

1Asnyhasiman96@gmail.com, 2putuanom@unud.ac.id

aProgram Studi S1 DestinasiPariwisata, FakultasPariwisata,UniversitasUdayana, Jl. Dr. R. Goris, Denpasar, Bali 80232 Indonesia

\begin{abstract}
Interesting tourist attractions that are not yet known by many people, one of them such as Maria Golo Curu Cave has a great opportunity to be used as a religious tourism destination in the City of Ruteng, Manggarai Regency, but a very unfortunate phenomenon that its development has not been maximized.

The purpose of this study is to identify existing attractions, such as natural, cultural, artificial attractions and maximize the development of Golo Curu as a religious tourism destination by using SWOT analysis which is an analysis based on strengths, weaknesses, opportunities and threats.

The results of the study concluded that, the advantage of the Golo Curu Maria Cave is the natural beauty that is still beautiful and unspoiled by human hands, not only as a place to pray but also as a place to relax and become a beautiful photo spot. The disadvantage is, access to the damaged and disturbing Golo Curu visitors, lack of maximum management and maintenance that is lacking, does not have parking space, and is associated with less commendable community ethics. Thus, the priority of developing religious tourism with the SWOT approach is to preserve the attractiveness and culture of religious activities, improve access to the Golo Curu, improve existing management, provide parking, support each organization participating in tourism activities, support existing tourism services so that the creation of tourism employment opportunities, involving rural communities in every decision-making and every tourism activity.
\end{abstract}

Keywords: Attraction, Development, Religious Tourism, SWOT Approach

\section{PENDAHULUAN}

Pariwisata telah menjadi sektor andalan dalam pembangunan ekonomi karena kegiatannya mendorong perkembangan beberapa sektor ekonomi nasional seperti meningkatkan peluang kerja, menggugah industri-industri baru yang berkaitan dengan jasa-jasa wisata, menambah permintaan akan hasil-hasil pertanian dan juga memperluas pasar barang-barang lokal.

Daya tarik wisata menjadi hal penting dan utama dalam kegiatan pariwisata.Sebuah destinasi dengan daya tarik yang memiliki keunikan, keindahan dan nilai yang berupa keanekaragaman kekayaan alam, budaya dan hasil buatan manusia akan menjadi sasaran atau tujuan kunjungan wisatawan, dan memiliki potensi untuk pengembangan pariwisata yang mempunyai pengaruh penting dalam satu atau lebih aspek, seperti pertumbuhan ekonomi, sosial, dan budaya, pemberdayaan sumber daya alam, daya dukung lingkungan hidup, serta pertahanan dan keamanan.

Kegiatan berwisata tidak hanya untuk berekreasi atau mencari hiburan semata. Ada beberapa orang atau kelompok yang memanfaatkan kegiatan berwisata di bidang religius dengan mengunjungi tempat khusus umat beragama, makam, tempat beribadah yang bertujuan untuk lebih mendekatkan diri kepada Tuhan, mendapatkan pengalaman rohani, meminta restu dan petunjuk dari yang Maha Kuasa. Sebagai contoh, seorang Katolik yang melakukan ziarah ke Vatikan, penganut Budha yang berkunjung ke Nepal, ziarah umat Muslim ke makam Wali Songo dan lain-lain.

Perkembangan pariwisata dewasa ini menyebabkan penumpukan wisatawan di suatu objek sehingga mengakibatkan kecendrungan untuk beralih ke objek wisata relatif yang belum berkembang pesat. Pergeseran inilah yang mengakibatkan timbulnya pariwisata minat khusus karena adanya motivasi khusus yang dimiliki wisatawan untuk mengadakan perjalanan alternatif. Pariwisata minat khusus dilakukan atas dasar minat dan motivasi khusus wisatawan untuk melakukan kunjungan dan terlibat dalam suatu wisata yang spesifik dengan menekankan unsur kegiatan yang unik dan pengalaman yang berkualitas. Meningkatnya kompleksitas hidup dan perkembangan tingkah laku kearah 
materialistik menyebabkan timbulnya kejenuhan dalam kehidupan manusia.Mereka berusaha mencari sesuatu yang baru sebagai sarana untuk mencari ketenangan batin, yang dalam pencapaiannya memerlukan sesuatu yang praktis, plural dan mudah dikonsumsi. Seiring dengan timbulnya kejenuhan tersebut, dalam masyarakat timbul aktivitas yang dapat menjawab kebutuhan manusia modern saat ini yaitu dengan aktivitas wisata religi.

Gua Maria Golo Curu yang terletak di Kota Ruteng, Manggarai, meiliki daya tarik yang berpotensi untuk dikembangkan sebagai sebuah wisata religi. Golo Curu belum sepenuhnya dieksplorasi, dikembangkan dan dikelola secara optimal oleh pemerintah sebagai objek wisata yang ideal.Selain itu masih banyak masyarakat yang belum menyadari potensi Gua Maria Golo Curu dan hal tersebut menjadi salah hambatan dalam mengenbangkan Golo Curu sebagai wisata religi yang ada di Kota Ruteng.

Penelitian ini menganalisis daya tarik yang dimiliki Gua Maria Golo Curu, baik daya tarik alam, buatan dan budaya keagamaan.Penelitian ini juga menganalisi potensi untuk mengembangkan Golo Curu sebagai wisata religi dilihat dari kekuatan yang ada dan peluang juga kelemahan dan ancman yang menjadi penghambat dalam pengembangannya.

\section{METODE PENELITIAN}

Penelitian ini dilakukan di Gua Maria Golo Curu yang berada di Keluharan Karot.Objek wisata tersebut masih berada dalam Kecamatan Langke Rembong yang terletak di Kota Ruteng, Kabupaten Manggarai.Batasan ruang lingkup permasalahan dalam penelitian ini yaitu: (1) analisis potensi menggunakan konsep daya tarik budaya, daya tarik alam dan daya tarik buatan. (2) Strategi pengembangan Gua Maria Golo Curu.

Jenis data yang digunakan dalam penelitian ini adalah data kualitatif dan data kuantitatif. Teknik pengumpulan data menggunakan teknik observasi, teknik wawancara, teknik studi pustaka (Moleong, 2012; Sugoyono, 2014; Suryawan dan Mahagangga, 2017).

SWOT membandingkan antara faktorfaktor eksternal yang merupakan peluang (opportunities) dan ancaman (threats) dengan faktor-faktor internal yang merupakan kekuatan (strengths) dan kelemahan (weaknesses). Kombinasi faktor internal dengan faktor eksternal yaitu : (1) Strategi SO (Strengths Opportinities), (2) Strategi ST (Strengths Threats), (3) Strategi WO (Weaknesses Opportunities), (4)Strategi WT (Weaknesses Threats) (Arikunto, 2006).

\section{HASIL DAN PEMBAHASAN}

Golo Curu dulunya merupakan kampung tua dari salah satu Klan di Karot Ruteng yang disebut Klan Curu.Lokasi di sekitaran Golo Curu juga merupakan pekuburan ulayat bagi masyarakat Karot. Golo Curu berada di Kelurahan Karot, Kecamatan Langke Rembong, persis terletak di pusat kota dan mudah untuk dijangkau oleh masyarakat. Terdapat Gua Maria di atas bukit Golo Curu yang dijadikan warga sekitar untuk berdoa. Sebelum memasuki Golo Curu, terdapat gapura selamat datang yang bertuliskan "Taman Doa" dan akan terlihat sebuag Salib Tuhan Yesus lalu dilanjutkan dengan 14 relief perhentian yang merupakan kisa sengsara penyaliban Tuhan Yesus.

Golo Curu menjadi tujuan masyarakat untuk berwisata khususnya berwisata dalam bidang rohani. Kegiatan yang satu ini menjadi kegiatan wisata yang berbeda dikarenakan setiap masyarakat atau pengunjung yang datang ke tempat wisata ini ialah orang-orang yang melakukan kegiatan beribadah dan tentu saja mereka yang bermayoritas Katolik.Berbeda dari kegiatan wisata lainnya yang mencari kesenangan dunia semata, wisata religi dimaknai sebagai kegiatan wisata ke tempat yang memiliki makna khusus bagi umat beragama. Wisata religi ini banyak dihubungkan dengan niat dan tujuan sang wisatawan untuk memperoleh berkah, rahmat, dan hikmah dalam kehidupannya. Wisata ini menjadi tujuan bagi mereka yang ingin mendapatkan kedamaian dan kebahagiaan baik pikiran, jiwa maupun raga, dan mendalami iman juga kepercayaan kepada apa yang mereka percayai. Tetapi tidak jarang pula untuk tujuan tertentu seperti untuk mendapat restu, kekuatan batin dan juga keteguhan iman.Secara substansial, wisata religi adalah perjalanan keagamaan yang ditunjuk untuk memenuhi dahaga spiritual, agar jiwa yang kering kembali basah oleh hikmah-hikmah religi. 


\section{Daya Tarik Gua Maria Golo Curu}

Salah satu potensi Nusantara yang memiliki banyak ketertarikan alam adalah Kota Ruteng.Kota $\mathrm{n}$ Ruteng memiliki Taman Wisata Alam (TWA) yang ditetapkan sebagai hutan konservasi oleh Dapartemen Pertanian pada Tahun 1993. Golo Curu menjadi salah satu tempat yang tidak seharusnya dilewatkan jika berwisata ke Kota Ruteng. Daya tarik alam yang ada di sekitarnya menjadi referensi bagi wisatawan untuk berkunjung.

Dengan berada di Bukit Golo Curu, wisatawan dapat melihat panorama $360^{\circ}$ wajah Kota Ruteng dan persawahan Watu Alo. Kelebihan inilah yang menjadikan Golo Curu bukan hanya sebagai tempat untuk berdoa, tetapi juga sebagai tempat berekreasi, camping, spot berfoto dan kegiatan lainnya.

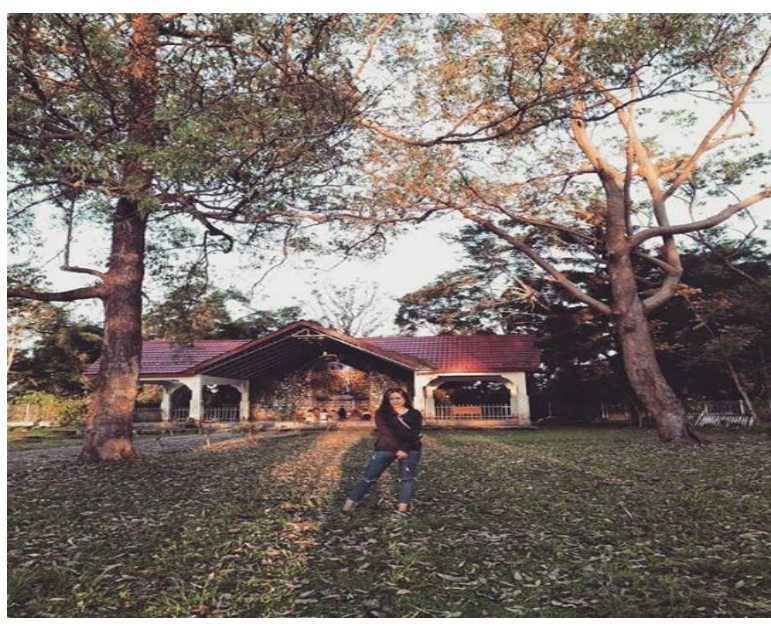

Gambar 1.Foto pengunjung di Golo Curu

Sumber: Dokumentasi pengunjung, Instagram:

@jujumbana

Gambar 3.menunjukkan ketertarikan pengunjung untuk mengadabadikan moment indah saat berada di Gua Maria Golo Curu. Karena keindahan alamnya itulah banyak orang yang berdatangan untuk mengabadikan moment-moment indah, berfoto ria di atas Bukit Golo Curu atau sekedar menikmati alam ciptaan Tuhan.

\section{Daya Tarik Budaya}

Wisata religi di Kota Ruteng dapat digolongkan dalam kegiatan pariwisata berdasarkan objek, tepatnya religion tourism, meupakan perjalanan wisata yang motivasinya untuk menyaksikan atau melihat upacara-upacara keagamaan, dan berdasarkan saat atau waktu berkunjung yang tergolong dalam occasional tourism, merupakan kegiatan perjalanan wisata yang dihubungkan dengan kejadian maupun event.

Gua Maria Golo Curu menjadi ramai dikunjungi oleh wisatawan pada bulan-bulan tertentu seperti bulan Mei dan bulan Oktober (bulan novena) karena pada bulan-bulan tersebut devosi umat beriman didedikasikankepada Bunda Maria yang terberkati dan merupakan kesempatan untuk melakukan penghormatan iman dan kasih yang diverikan umat Katolik di setiap bagian dunia kepada Sang Ratu Surga.Selain itu wisatawan juga berdatangan pada akhir Maret (masa prapaskah) atau pada bulan April untuk mengikuti prosesi Jalan Salib yang dilakukan untuk mengenang kisah sengsara dan penderitaan yang dilalui Yesus Kristus sebelum wafat salib. Forum Tata Kelola Pariwisata (FTKP) memutuskan untuk melakukan sebuah gebrakan dengan melakukan jalan salib sadar wisata dan menjadikannya ritinitas umat Katolik setiap tahunnya.

Sudah banyak masyarakat, baik kelompok organisasi ataupun perorangan yang melaksanakan kegiatan beribadah di Gua Maria. Beberapa diantaranya, lebih dari 300 Devosan Maria berziarah ke Gua Maria Golo Curu, Komunitas Basis Gerejani (KBG) yang juga melaksana kegiatan zirah rohani, Dharma Wanita Persatuan Kabupaten Manggarai yang mengadakan kegiatan prosesi jalan salib. Selain itu ada juga Orang Muda Katolik (OMK) yang melaksanakan prosesi jalan salib pada masa prapaskah.

Tidak hanya yang berkelompok, ada juga masyarakat yang pergi berdoa ke Gua Maria secara perseorangan untuk berdoa dan menyampaikan itensi secara pribadi.

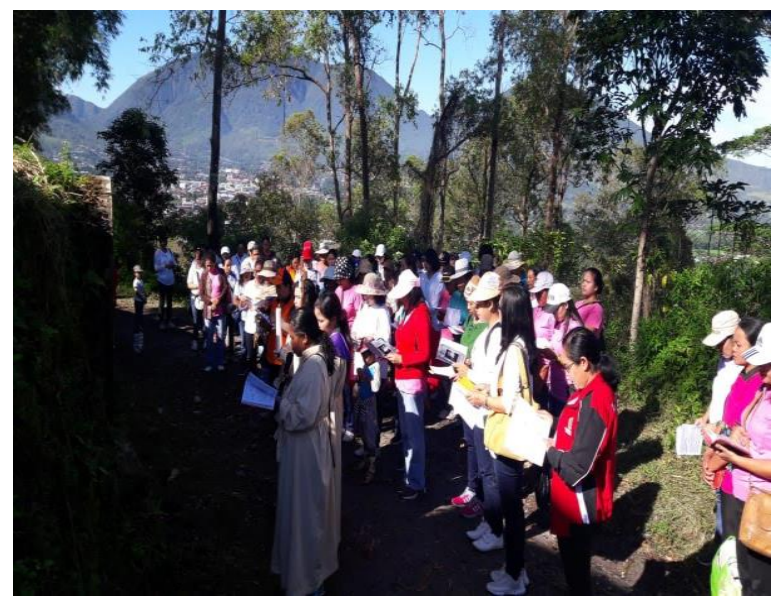

Gambar 2.Prosesi Jalan Salib

Sumber: Dokumentasi Peneliti 2018 


\section{Daya Tarik Buatan}

Keberadaan Golo Curu saat ini dan potensi yang dimilikinya mulai mendapat perhatian. Bukan hanya pemerintah yang memberikan perhatian tetapi juga beberapa lembaga organisasi yang mulai melirik Golo Curu dan ingin turut serta mengembangkannya sebagai salah satu objek wisata yang dimiliki Kota Ruteng.

Sebuah organisasi kemahasiswaan yang bernama IMMADA (Ikatan Mahasiswa Manggarai Udayana) menyelenggarakan serangkaian acara di Golo Curu. Diawali dengan perayaan ekaristi bersama warga yang hadir, setelah itu dilanjutkan dengan pentas seni dan pameran kesenian. Acara ini diselenggarakan dalam rangka mendukung Golo Curu dan mempromosikannya sebagai destinasi wisata religi yang ada di Kota Ruteng serta membantu pembangunan Gereja Paroki St. Fransiskus Asisi Karot. Ada juga LSM (Lembaga Swadaya Masyarakat) bernama Sejahtera Desaku dan Lingko Nanga Nasa yang mengadakan kegiatan penanaman pohon dan penghijauan Golo Curu agar keindahan dan keasrian alamnya tetap terjaga dan membuat setiap wisatawan yang datang berkunjung merasa nyaman.

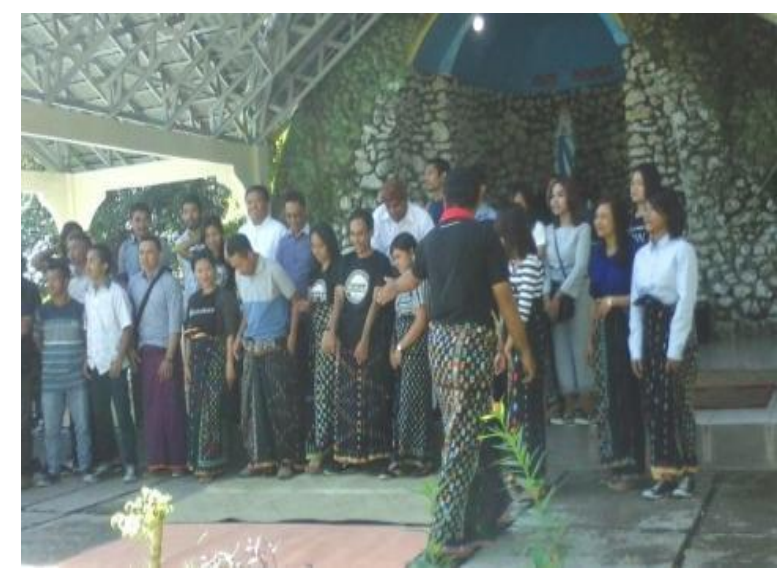

Gambar 3.Anggota IMMADA

Sumber: dokumentasi peneliti 2016

\section{Strategi Pengembangan Gua Maria Golo Curu Sebagai Daya Tarik Wisata Religi}

Sangatlah penting untuk mengetahui daya tarik apa saja yang dimiliki oleh Gua Maria Golo Curu. Penting juga untuk menganalisis kekuatan-kekuatan juga kelemahan-kelemahan yang dimiliki sehingga nantinya dapat diminimalisir dan dapat dikembangkan sebagai sebuah destinasi wisata religi.Pengembangannya diharapkan dapat berdampak positif pada sektor-sektor lainnya sehingga memacu peningkatan taraf kehidupan masyarakat, kesejahteraan masyarakat, kesempatan kerja dan pendapatan masyarakat.

\section{Kekuatan (Strenght)}

Kekuatan merupakan salah faktor penting yang dianggap sebagai potensi dalam mengembangkan suatu destinasi wisata. Gua Maria Golo Curu sebagai objek wisata religi memiliki kekuatan yang menarik perhatian wisatawan. Bukan hanya sebagai tempat berdoa, beberapa pengunjung juga berekreasi, mengabadikan moment saat berada di Golo Curu, atau sekedar menikmati pemandangan Kota Ruteng dan persawahan Watu Alo. Sebelum memasuki Golo Curu, pengunjung akan mendapati 14 relief pemberhentian kisah sengsara Yesus atau dikenal sebagai jalan salib. Relief jalan salib kisah sengsara Yesus biasanya hanya bisa di temui di dalam gereja. Gua Maria Golo Curu bukan hanya sebagai tempat berdevosi kepada Bunda Maria tetapi juga sebagai tempat melaksanakan jalan salib. Tidak jauh dari kawasan Gua Maria, terdapat makan pahlawan dan makam orang-orang penting dalam sejarah Manggarai. Selain berdoa di Gua Maria, pengunjung juga bisa memanjatkan doa di makan pahlawan sebagai penghargaan ungkapan terima kasih atas jasa-jasanya.

\section{Kelemahan (weaknesses)}

Selain kekuatan, Golo Curu juga memiliki kelemahan yang jika tidak diperhatikan dan diabaikan oleh pemerintah dapat mengancam pengembangannya sebagai destinasi wisata religi. Saat ini Golo Curu menjadi salah satu destinasi yang ditawarkan Dinas Pariwisata dan Budaya Kabupaten Manggarai kepada wisatawan nusantara dan mancanegara. Pemkab Manggarai, gereja dan masyrakat mulai memberikan perhatian kepada wisata religi ini. Infrastruktur dasar seperti jalan sudah disediakan. Namun kondisi jalan saat ini berlubang dan berpasir, tidak adanya pembatas jalan, dan bertikungan tajam. Hal ini tentu meresahkan setiap pengunjung yang datang. Manajemen Golo Curu masih pada standar yang biasa, seperti Golo Curu masih belum mempunyai data pengunjung setiap tahunnya dan kondisi Golo Curu yang 
sewaktu-waktu dibersihkan saat akan diselenggarakan sebuah acara. Fasilitas yang seharusnya dibutukan di Golo Curu belum sepenuhnya disediakan, seperti belum ada kursi bagi pengunjung yang datang beribadah, atau masih kurangnya penerangan sepanjang jalan ke Golo Curu. Kelemahan lainnya ialah sampai saat ini Golo Curu masih belum memiliki lahan parkir. Sulit bagi para pengunjung untuk mencari tempat memarkirkan kendaraan. Selain itu adanya kaum vandalism yang kurang yang menjadi salah satu kelemahan Golo Curu. masih ada beberapa kelompok masyarakat khususnya kaum remaja yang kurang memberikan perhatian dengan merusak lingkungan Golo Curu. Kurangnya partisipasi interaktif secara tidak langsung menjadi ancaman bagi Golo Curu. Partisipasi interaktif merupakan partisipasi rakyat dalam analisis bersama mengenai pengembangan perencanaan aksi dan pembentukan atau penekanan lembaga lokal.Pengambilan keputusan bersifat lokal dari kelompok-kelompok untuk menentukan bagaimana ketersediaan sumber daya yang digunakan.Hal yang ditakutkan ialah jika pengambilan keputusan ditetapkan oleh orang luar, maka dapat mengakibatkan masyarakat setempat tidak memiliki kekuasaan atau wewenang untuk menjaga potensi yang ada di lingkungannya.

\section{Ancaman (Threats)}

Dalam mengembangkannya sebagai objek wisata religi, tidak menutup kemungkinan munculnya berbagai ancaman. Ancamanancaman tersebut harus diperhatikan dengan seksama dan diminimalisir. Munculnya pesaing dengan menawarkan produk wisata yang berbeda dan lebih menarik menjadi salah satu ancaman bagi Golo Curu. Beberapa diantaranya seperti, Villa Alam Flores, Lodok (Spider web), ataupun air terjun Tengku Lese. Cuaca menjadi salah satu ancaman bagi lingkungan Golo Curu. Kebanyakan daerah yang ada di Pulau Flores memiki intensitas curah hujan yang tinggi dibandingkan dengan daerah lain, salah satunya ialah Kota Ruteng. Musim hujan yang panjang dan dengan curah hujan yang cenderung tinggi bisa menyebabkan longsor di beberapa daerah yang ada di Kabupaten Manggarai. Hal yang sama juga dikahwatirkan akan terjadi pada Golo Curu.

\section{Peluang (Opportunity)}

Salah satu faktor eksternal yang harus diindentifikasi ialah peluang. Saat ini Golo Curu menjadi satu-satunya wisata minat khusus yaitu wisata religi yang yang ada di Kota Ruteng. Hadirnya Golo Curu sebagai wisata religi yang ada di Kota Ruteng mebuat industri pariwisata atau jasa pelayanan mulai bermunculan. Beberapa usaha-usaha wisata yang ditawarkan di Kota Ruteng diantaranya Hotel Revaya, Hotel Ranaka, Restoran AGP, Allibe Pizza, Café D’Mbembos, Café Kopi Mane dan beberapa lainnya. Selain iti mulai munculnya Non Government Organization yang juga sering melakukan aktivitas kemasyarakatan, termasuk diantaranya dalam bidang pariwisata seperti LSM Sejahtera Desaku dan LSM Lingko Nanga Nasa. Munculnya usaha wisata saat ini juga membuat terbukanya peluang kerja bagi masyarakat. 


\section{Tabel 1}

\section{Analisis SWOT dalam Mengembangkan Golo Curu sebagai Obyek Wisata Religi}

\begin{tabular}{|c|c|c|}
\hline Eksternal & $\begin{array}{l}\text { Strengths / Kekuatan (S) } \\
\text { 1. Menawarkan panorama } 360^{\circ} \text { dari } \\
\text { Kota Ruteng dan persawahan } \\
\text { Watu Alo. } \\
\text { 2. Memiliki relief-relief } \\
\text { pemberhentian kisah sengsara } \\
\text { Yesus. } \\
\text { 3. Menjadi tempat untuk berziarah ke } \\
\text { makam pahlawan. }\end{array}$ & $\begin{array}{l}\text { Weaknesses / Kelemahan (W) } \\
\text { 1. Kondisi jalan menuju Golo } \\
\text { Curu yang meresahkan dan } \\
\text { mengkhawatirkan para } \\
\text { pengunjung. } \\
\text { 2. Masih kurangnya manajemen } \\
\text { pada Golo Curu. } \\
\text { 3. Tidak memiliki lahan untuk } \\
\text { parkir. } \\
\text { 4. Adanya kaum vandalism. } \\
\text { 5. Kurangnya partisipasi } \\
\text { interaktif dari masyarakat } \\
\text { Curu. }\end{array}$ \\
\hline $\begin{array}{l}\text { Opportunities/Peluang (0) } \\
\text { 1. Menjadi satu-satunya } \\
\text { minat khusus yang ada } \\
\text { di Kota Ruteng. } \\
\text { 2. Munculnya industri } \\
\text { pariwisata } \\
\text { 3. Terbukanya lapangan } \\
\text { kerja. } \\
\text { 4. Munculnya } \\
\text { Government } \\
\text { Organization. }\end{array}$ & $\begin{array}{l}\text { Strategi (S-0) } \\
\text { 1. Melestarikan lingkungan dan } \\
\text { kebudayaan keagamaan, } \\
\text { memaksimalkan pengembangan } \\
\text { Golo Curu. } \\
\text { 2. Memperhatikan perkembangan } \\
\text { industri pariwisata, membuka } \\
\text { lapangan kerja baru. } \\
\text { 3. Bekerja sama dengan Lembaga } \\
\text { Swadaya Masyarakat. } \\
\text { 4. Pemeliharaan fasilitas yang sudah } \\
\text { disediakan sebelumnya. }\end{array}$ & $\begin{array}{l}\text { Strategi (W-O ) } \\
\text { 1. Memperbaiki kondisi jalan } \\
\text { menuju Golo curu. } \\
\text { 2. Meperbaiki manajemen Golo } \\
\text { Curu. } \\
\text { 3. Menyediakan lahan parkir } \\
\text { bagi pengunjung. } \\
\text { 4. Pemberdayaan sumber daya } \\
\text { manusia untuk menjadi } \\
\text { tenaga kerja, khususnya di } \\
\text { bidang pariwisata }\end{array}$ \\
\hline $\begin{array}{l}\text { Threats / Ancaman (T) } \\
\text { 1. Adanya pesaing yang } \\
\text { menawarkan produk } \\
\text { wisata yang lebih } \\
\text { menarik seperti Villa } \\
\text { Alam Flores atau Lodok } \\
\text { (spider web). } \\
\text { 2. Cuaca yang buruk bisa } \\
\text { menjadi ancaman bagi } \\
\text { Golo Curu seperti curah } \\
\text { hujan yang besar. }\end{array}$ & $\begin{array}{l}\text { Strategi (S-T) } \\
\text { 1. Mengembangkan dan memelihara } \\
\text { keunikan Gua Maria Golo Curu. } \\
\text { 2. Menjaga dan merawat kelestarian } \\
\text { alam di sekitar Gua Maria Golo } \\
\text { Curu. } \\
\text { 3. Mengadakan sosialisasi kepada } \\
\text { masyarakat mengenai potensi } \\
\text { yang dimiliki Gua Maria Golo Curu } \\
\text { dan potensinya yang dapat } \\
\text { dikembangkan sebagai sebuah } \\
\text { objek wisata religi }\end{array}$ & $\begin{array}{l}\text { Strategi (W-T) } \\
\text { 1. Menata Golo Curu menjadi } \\
\text { lebih rapi dan indah. } \\
\text { 2. Mengikutsertakan } \\
\text { masyarakat Curu dalam } \\
\text { mengembangkan Golo Curu. } \\
\text { 3. Pemerintah bekerja sama } \\
\text { dengan masyarakat untuk } \\
\text { membuat aturan dan sanksi } \\
\text { bagi kaum masyarakat } \\
\text { vandalism. }\end{array}$ \\
\hline
\end{tabular}

Sumber: analisis penelitian 2018

Kombinasi faktor internal dan eksternal:

Strategi So (Strength - Opponuties) meliputi : (1) Lingkungan alam yang ada di Golo Curu harus dilestarikan dan ditata rapi agar terlihat indah, begitu juga dengan kegiatan keagamaan seperti Devosi kepada Maria, profesi Kisah Sengsara Yesus dan ritual keagamaan lainnya mengingat kedua hal tersebut menjadi daya tarik bagi wisatawan untuk berkunjung ke Gua Maria Golo Curu. (2) Komitmen pemerintah dalam mengerahkan tenaga dalam membangun dan mengembangkan sektor industri pariwisata merupakan modal dasar. Oleh karenanya, diharapkan pemerintah memperhatikan dengan seksama dan mendukung indutsri pariwisata yang mulai bermunculan. Dengan hadirnya industri pariwisata maka peluang terbukanya lapangan kerja baru semakin tinggi. (3) Golo Curu sebagai sebuah destinasi wisata religi, mendapat banyak perhatian baik dari pemerintah, masyarakat, organisasi atapun suatu lembaga. Salah satu lembaga di Kota Ruteng bernama LSM Sejahtera Desaku 
mendukung setiap kegiatan yang berdampak baik bagi daerahnya, seperti kegiatan di bidang pariwisata.(4) Masyarakat yang ada di sekitar Golo Curu juga memiliki peran penting. Tidak hanya menjaga kelestarian dan kebersihannya, masyarakat juga harus bisa merawat fasilitas-fasilitas sudah disediakan sebelumnya oleh pemerintah. Hal tersebut bisa sangat membantu dengan tujuan dana pembangunan Golo Curu bisa digunakan untuk menyediakan fasilitas lain yang belum ada sebelumnya.

\section{Strategi ST (Strengths -}

Threats)meliputi : (1) Pemerintah Kabupaten dan Dinas Pariwisata Manggarai memberikan perhatian yang lebih pada Golo Curu. Mereka sadar bahwa Gua Maria Golo Curu memiliki potensi, oleh sebab itu pemerintah mulai membenahi dan mengembangkan semaksimal mungkin agar nantinya Golo Curu menjadi lebih baik lagi dari sebelumnya. Selain itu pemerintah, masyarakat dan pemuka agama bersama-sama melestarikan kegiatan keagamaan yang adalah keunikan dari Gua Maria Golo Curu. (2) Kelestarian alam Golo Curu harus tetap dijaga dan dirawat untuk meminimalisir kejadian ata bencana dari musim dan cuaca yang buruk, selain itu juga agar tetap terlihat asri dan membuat para pengunjung merasa nyaman. (3) Dinas Pariwisata Kabupaten Manggarai harus mengadakan sosialisasi mengenai pariwisata. Sosialisasi yang dilakukan bertujuan memberitahu warga bahwa Gua Maria Golo Curu memiliki potensi yang dapat dikembangkan sebagai sebuah destinasi wisata religi.

\section{Strategi wo (Weaknesses -} Opportunities) meliputi : (1) Jalan sepanjang Golo Curu terbilang kecil, jalanannya yang bertebing belum dibuatkan pembatas, masih adanya jalan yang berlubang dan berpasir. Kondisi tersebut jelas meresahkan dan mengancam keselamatan para pengunjung.Perlu ada tindakan dari pemerintah untuk memperbaiki jalan menuju Golo Curu sehingga perjalanan pengunjung menjadi mudah dan aman.(2) Golo Curu sebagai destinasi wisata religi masih sangat disayangkan dan tampak miris dikarenakan belum memiliki struktur kepengurusan. Tempat tersebut sewakktu-waktu akan dibersihkan saat akan diadakannya kegiatan yang berskala besar. Tidak ada orang yang ditugaskan untuk membersihkan area tempat berdoa atau sekedar membersihkan bekasbekas lilin yang dibakar saat berdoa. (3) Pemerintah bekerja sama dengan masyarakat terkait menyediakan lahan parkir. Parkiran dibuat agar pengunjung yang berkunjung ke Golo Curu tidak memarkirkan kendaraan di lahan miliki warga melainkkan di parkiran yang sudah disediakan khusus untuk pengunjung Golo Curu. (4) Dengan adanya industri pariwisata di Kota Ruteng maka terciptanya peluang kerja bagi masyarakat khususnya pemberdayaan sumber daya manusia di bidang pariwisata. .

\section{Strategi WT (Weaknesses - Threats)}

meliputi :(1)Gua Maria dan lingkungan di sekitar Golo Curu harus ditata sebaik mungkin. Menjadikan Golo Curu indah dan tertata rapi akan meninggalkan kesan yang baik dan pengunjung bisa memiliki pengalaman menarik saat berada di Gua Maria Golo Curu. Begitupun sebaliknya, jika Golo Curu tidak diperhatikan dan dibiarkan terbengkelai maka akan terkesan buruk di mata pengunjung. (2) Warga Curu sebagai warga asli Klan Curu yang mana memiliki hak penuh terhadap Golo Curu harus berpartisipasi secara interaktif. Partisipasi interaktif merupakan partisipasi masyarakat dimana pengambilan keputusan bersifat lokal dari kelompok-kelompok untuk menentukan bagaimana ketersediaan sumber daya yang digunakan.Jika pengambilan keputusan ditentukan oleh orang luar maka dapat mengakibatkan masyarakat lokal tidak memiliki kekuasaan atau wewenang untuk menjaga potensi yang ada di lingkungannya. (3) Karena masih adanya kaum vandalism yang merusak citra Gua Maria sebagai tempat untuk berdoa bagi umat kristiani, maka dari itu perlu dilakukannya pengawasan dari pihak keamananagar tidak ada lagi gangguan dari beberapa oknum yang meresahkan para pengunjung. (4) Saat ini Labua Bajo menjadi destinasi prioritas yang berada di Kabupaten Manggarai Barat. Dengan semakin banyaknya wisatawan yang datang ke Labuan Bajo membuat industri pariwisata baru yang mulai bermunculan. Salah satu diantaranya ialah industri perjalanan pariwisata. Menjalin kerja sama dengan biro industri perjalanan akan memudahkan Pemeritah Kabupaten Manggarai untuk mempromosikan Gua Maria 
Golo Curu sebagai sebuah destinasi wisata religi. Hal tersebut menjadi mungkin dikarenakan kebanyakan wisatawan yang berkunjung ke Labuan Bajo ialah pendatang dari Eropa yang beragama katolik.

\section{KESIMPULAN}

Berdasarkan hasil penelitian, kesimpulan yang dapat ditarik oleh penulis bahwa potensi yang dimiliki oleh Gua Maria Golo Curu dapat dijabarkan sebagai berikut: (1) Daya tarik wisata yang ada pada Gua Maria Golo Curu ialah, daya tarik alam berupa keindahan alamnya yang menarik perhatian. Dari bukit Golo Curu pengunjung bisa menikmati indahnya hamparan persawahan dan pemandangan Kota Ruteng. Selain itu, Gua Maria Golo Curu menjadi tempat dilaksanakannya kegiatan keagamaan jalan salib sadar wisata setiap tahunnya dan menjadi tempat untuk berdevosi pada bulan khusus (Bulan Mei dan Bulan Oktober) yang merupakan kebiasaan umat kristiani. Tidak jarang juga Golo Curu menjadi tempat untuk diselenggarakannya sebuah kegiatan atau event, seperti contohnya kegiatan pentas seni yang dilaksanakan oleh Ikatan Mahasiswa Manggarai Udayana yang juga bertujuan untuk mempromosikan Golo Curu sebagai suatu destinasi wisata religi.(2) Golo Curu sebagai sebuah daya tarik tentunya memiliki kekuatan dan kelemahan. Adapun kekuatan yang dimiliki ialah bukan hanya sebagai tempat untuk berziarah dan berdoa, pengunjung juga bisa berekreasi dan menikmati keindahan alam dari atas bukit kecil tersebut. Sedangkan kelemahannya ialah manajemen yang belum maksimal dan akses menuju bukit yang rusak.

Adapun simpulan dari kombinasi faktor internal dan faktor eksternal menggunakan analisis SWOT untuk mengembangkan Golo Curu ialah memelihara dan melestarikan daya tarik eksisting, mendukung industri pariwisata yang mulai bermunculan dan lembaga kemasyarakatan yang berpartisipasi dalam kegiatan pariwisata, memperbaiki jalan yang rusak, memaksimalkan manajemen yang ada, menyediakan lahan parkir, mengembangkan Golo Curu sesuai dengan unsur-unsur pariwisata, menjalin kerja sama dengan biro perjalanan untuk mempromosikan dan menyebarluaskan daya tarik wisata Golo Curu, memberikan sosialisasi kepada masyarakat mengenai betapa pentingnya menjaga kelestarian alam, melibatkan masyarakat setempat dalam pembuatan rencana pengembangan wisata religi di Gua Maria Golo Curu.

\section{DAFTAR PUSTAKA/REFERENSI}

Anom, I. Putu. 2014. Potensi Kepariwisataan Provinsi Nusa Tenggara Timur (Studi Kasus di Kawasan Pariwisata Komodo). Jurnal Analisis Pariwisata, 14(1), 1410-3729

Arikunto, S.. (2006). Prosedur penelitian suatu pendekatan praktik. Jakarta: Rineka

Bungin, B. 2007.Penelitian Kualitatif. Prenamedia Group. Jakarta

Dyah Ivana Sari. 2010. Objek Wisata Religi Sunan Muria (Studi kehidupan Sosial dan Ekonomi Masyarakat Desa Colo, Kecamatan Dawe, Kabupaten Kudus). Skripsi.Surakata : Universitas Sebelas Maret

Hanum, Fani Mutia. 2014. Implementesi Rencana Strategi Pengembangan dan Pelestarian Destinasi Wisata Cagar Budaya Banten Lama di Dinas Kebudayaan dan Pariwisata Provinsi Banten. Tugas Akhir. Serang : Universitas Sultan Ageng Tirtayasa

Hariyanto, O. I. B. (2016). Destinasi Wisata Budaya Dan Religi Di Cirebon.Jurnal Ecodemica, 4(2), 214-222

HASAN, S. M. (2016). Strategi Pengembangan Wisata Kota Cirebon Menuju Destinasi Utama Wisata Religi.Skripsi.Yogyakarta : Universitas Muhammadiyah

Kadarwati, A. (2008). Potensi dan Pengembangan Obyek Wisata Kota Lama Semarang Sebagai Daya Tarik Wisata di Semarang (Doctoral dissertation, Universitas Sebelas Maret)

Kusmayadi \& Endar Sugiarto, 2000.Metodologi Penelitian Dalam Bidang Kepariwisataan.PT. Gramedia Pustaka. Jakarta

Moleong, L. 2012. Metodologi Penelitian Kualitatif. GP Press Group. Jakarta

Naicea, Sriyanti. (2018). Devosi Yang Sehat Kepada Santa Perawan Maria Dalam Gereja Katolik. Tugas Akhir. Yogyakarta : Universitas Sanata Dharma 
Paat, F. C. (2014). Analisis Potensi dan Pengembangan Pariwisata di Kota Tomohon (Doctoral dissertation, Program Studi Ilmu Ekonomi FEB-UKSW)

Pendit, N. S. 2002. Ilmu Pariwisata. Pradnya Paramita. Jakarta

Pitana, I. 2009. Pengantar Ilmu Pariwisata. Andi. Yogyakarta

Rangkuti, F. 2011. SWOT: Belanced Scorecard. Gramedia Pustaka Utama. Jakarta

Rangkuti, F. 2015. Analisis SWOT: Teknik Membedah Kasus Bisnis. Gramedia Pustaka Utama. Jakarta

Republik Indonesia. 2009. Undang Undang Republik Indonesia No.10 Tahun 2009 Tentang Kepariwisataan. Jakarta Sekretariat Negara

Rosetya, S. S. (2010). POTENSI GOA MARIA SENDANG RATU KENYA SEBAGAI KAWASAN WISATA ROHANI DI KABUPATEN WONOGIRI (Doctoral dissertation, Universitas Sebelas Maret)

Sugiyono.2014.MetodePenelitianPendidikan. Alfabeta. Bandung

Sukarno, Teguh Hadi. 2007. Strategi Pengembangan Rekreasi di Objek Wisata Tanjung Benoa.Tesis : Universitas Udayana.

Suryawan Ida Bagus dan Mahagangga, I Gusti Agung Oka. 2017. Penelitian Lapangan 1. Denpasar: Cakra Press dan Fakultas Pariwisata.

Sumber lainnya :

http://www.utiket.com/id/obyekwisata/ruteng/panduan-wisataruteng.html (Diakses pada tanggal 24 September 2018 pukul 17.25 WITA)

https://tourism.nttprov.go.id/objek/463panorama kota ruteng dari bukit golo_curu (Diakses pada tanggal 26 September 2018 pukul 16:05 WITA)

http://www.narareba.com/2013/08/daftarparoki-kevikepan-ruteng.html (Diakses pada tanggal 24 Mei 2017 pukul 14:25 WITA)

http://baltyra.com/2010/09/29/lovely-ruteng/
(Diakses pada tanggal 27 Maret 2019 pukul 22:47 WITA)

http://www.pengertianku.net/2015/03/pengertia n-analisis-swot-dan-manfaatnya.html (Diakses pada tanggal 4 April 2019 pukul 23:45 WITA)

http://pengertianparaahli.com/pengertia n-contoh-analisis-swot/

(Diakses pada tanggal 5 April 2019 pukul 14:05 WITA)

https://www.jurnal.id/id/blog/2017-manfaatfaktor-yang-memengaruhi-dan-contohanalisis-swot/

(Diakses pada tanggal 7 April 2019 pukul 15:26 WITA)

https://www.maxmanroe.com/vid/manajemen/p engertian-dokumentasi.html (Diakses pada tanggal 1 Juli 2019 pukul 19:10 WITA) 